\title{
Antioxidant and Anticancer Activities of Different Constituents Extracted from Egyptian Prickly Pear Cactus (Opuntia Ficus-Indica) Peel
}

Faten M. Abou-Elella and Rehab Farouk Mohammed Ali*

Department of Biochemistry, Faculty of Agriculture, Cairo University, 12613, Giza, Egypt

*Corresponding author: Rehab Farouk Mohammed Ali, Department of Biochemistry, Faculty of Agriculture, Cairo University, 12613, Giza, Egypt, Tel: 002-01282959994; E-mail: malk_anany@yahoo.com

Received date: 29-Sep-2014, Accepted date: 13-Oct-2014, Published date: 20-Oct-2014

Copyright: (c) 2014 Abou-Elella FM et al. This is an open-access article distributed under the terms of the Creative Commons Attribution License, which permits unrestricted use, distribution, and reproduction in any medium, provided the original author and source are credited.

\begin{abstract}
Different extracts and their fractions of the Opuntia ficus-indica peel were evaluated for anticancer and antioxidant activities. The anticancer activity was tested using trypan blue technique against Ehrlich ascites carcinoma cells (EACC). Antioxidant activity was determined using the, $\alpha$ - diphenyl- $\beta$-picrilhydrazyl radical-scavenging assay system, and compared with those of the positive controls of butylated hydroxytoluene (BHT). Chloroform and ethanol extracts exhibited the strongest antioxidant and anticancer activity in the assay system. The ethanolic extract was further separated into nine fractions, designated as (E1-E9), by TLC. In most cases, E8 and E9 fractions have the strongest antioxidantandanticanceractivitiesthereforethesetwofractionswereidentifiedusingdifferent spectroscopic tools (MS, IR, 1H-NMR and 13C-NMR). The compounds were chemically identified as 17-hydroxy betanin and betanin. The total phenolic contents, tannins, flavonoids, betanins and reducing powers of the different extracts, and their fractions, were also measured. The antioxidant and anticancer potency showed significant relationship with the total phenolic content.
\end{abstract}

Keywords: Prickly pear cactus (Opuntia ficus-indica); Natural phytochemicals; Phenolic compounds; Antioxidant; Anticancer; 17hydroxy betanin; Betanin

\section{Introduction}

Several species of cactus pear plants belonging to the Cactaceae family are originated from Central America (Mexico). These species became widespread in semi-arid regions of the world, including Egypt. They are of special interest because they are one of the few crops that can be cultivated in areas which offer very little growth possibility for common fruits and vegetables (Han \& Feker [1]). About 1500 species of cactus are in the genus Opuntia and many of them produce edible and highly favored fruits. In addition, Mexicans have used Opuntia leaves and fruits for their medicinal benefits, such as treating arteriosclerosis, diabetes, and gastritis (Galati et al. [2]; CardadorMartinez et al. [3]). Numerous studies have evocated the analgesic and anti-inflammatory actions of the genus Opuntia by using their fruit extract (Galati et al. [2], Wu et al. [4]; Yeddes et al. [5]). Opuntia fruits and young stems have been traditionally used in folk medicine to treat diabetes, hypertension, asthma, burns, edema, and indigestion (Castanda-Andrade et al. [6]; Galati et al. [7]; Cardador-Martinez et al. [3]). In addition to their nutritional and medicinal properties, these plants contain compounds which have several commercial applications. One such compound is betalain, a water-soluble nitrogen-containing pigment and found in high concentrations in cactus pear plants (Castellar et al. [8], Diaz et al. [9]) in the form of betalamic acid. This acid is the chromophore common to all betalain pigments (Strack et al. [10]) and used as natural food colorants (Stintzing et al. [11]). The most important bio-active compounds detected also in cactus fruit are phenolic compounds (Kuti [12]), betacyanins, and betaxanthin pigments, all of which have potent antioxidant properties (Zakharova \& Petrova [13], Gentile et al. [14]). Phenolic compounds can be defined as substances possessing an aromatic ring, carrying one or more hydroxyl groups, including their functional derivatives (Andres-Lacueva et al. [15]). Their chemical structures and concentrations are quite variable and depend on the variety, ripening stages, and the kind of plant tissue (Wallace [16]). Glycosilated flavonols, dihydroflavonols, flavonones and flavonols have been found in Cactaceae plants and fruits (Kuti [17]). The antioxidant properties of the phenolic compounds in cactus pear plants makes the fruit an important product for preventing human health against degenerative diseases such as such as cancer, diabetes, hyperglycemia (Galati et al. [2]) hypercholesterolemia, arteriosclerosis and gastric diseases (Galati et al. [3]). The antioxidant activity of cactus fruit is twice as high as pears, apples, tomatoes, bananas, white grapes, and is comparable to red grapes and grapefruit (Butera,et al. [18]). Kuti [19] reported that the antioxidant effects are due to the major flavonoids encountered in cactus fruits. Flavonoids are more efficient antioxidants than vitamins, since phenolic compounds are able to delay pro-oxidative effects in proteins, DNA, and lipids by the generation of stable radicals (Shahidi, et al. [20]). Polyphenolic compounds in $\mathrm{O}$. ficus indica have been shown to induce a hyperpolarization of the plasma membrane and to raise the intracellular pool of calcium in human Jurkat T-cell lines (Aires et al. [21]).

The purpose of this work was to determine the content of total phenolics, total betalains, total flavonoids, total tannins, antioxidant activity, anticancer in different extract of peels prickly pear cactus (Opuntia ficus-indica) originating from Giza, Egypt, In addition, the phenolic constituents of the of peels prickly pear cactus were isolated and identified using different chromatographic techniques. 


\section{Materials and Methods}

\section{Chemicals and Reagents}

Folin-Ciocalteu reagent, 2, 2-diphenyl-1-picrylhydrazyl (DPPH), sodium carbonate and aluminum chlorid were purchased from Sigma Chemical Co., Ltd (St. Louis, MO, USA). Gallic acid, chloroform, ethyl acetate, ethanol, acetone, and methanol were purchased from E. Merck Co. (Darmstadt, Germany), and were distilled before use.

\section{Plant extraction}

Prickly pear fruits (Opuntia ficus indica) in the ripe stage were obtained from the local market, Giza, Egypt, in June 2013. Fresh and mature prickly pear fruits were carefully hand-peeled, and the peels (with a thickness of about 3-4 mm) were cut into small pieces and sun- dried. The dried parts were ground in an electric grinder (Braun Model 1021), passed through a $150-\mu \mathrm{m}$ mesh sieve, and stored in a freezer $\left(-25^{\circ} \mathrm{C}\right)$ until further use. The dried samples were sequentially extracted with $500 \mathrm{ml}$ each of chloroform, ethyl acetate, acetone, ethanol $80 \%$, ethanol, methanol and distilled water. Each fraction was separately evaporated using a rotary vacuum evaporator at $45^{\circ} \mathrm{C}$. The obtained extracts were kept in light-protected containers at $-25^{\circ} \mathrm{C}$ until further use.

\section{Phytochemical analysis}

\section{Determination of total polyphenols}

Total phenolic content of the all extracts was determined using the Folin-Ciocalteu assay system (AOCS [22]). The results were expressed as $\mu \mathrm{g}$ of gallic acid equivalent per $100 \mathrm{~g}$ dry weight (DW).

\section{Determination of total Flavonoids}

The total flavonoid content was determined using the Dowd method (Meda, et al. [23]). The total flavonoid content was determined using a standard curve with catechin $(0-100 \mathrm{mg} / \mathrm{L})$ as a standard. Total flavonoids content is expressed as $\mathrm{mg}$ of catechin equivalents (CE)/100 g DW.

\section{Determination of total Tannins}

The total tannin content in the extracts was determined by modified method of Polshettiwar et al. [24]. The sample $(0.1 \mathrm{~mL})$ was mixed with $0.5 \mathrm{~mL}$ of Folin-Denis reagent followed by $1 \mathrm{~mL}$ of $\mathrm{Na} 2 \mathrm{CO} 3$ $(0.5 \%, \mathrm{w}: \mathrm{v})$ solution and distilled water (up to $5 \mathrm{~mL}$ ). The absorbance was measured at $755 \mathrm{~nm}$ within $30 \mathrm{~min}$ of the reaction against the blank. The total tannin in the extract was expressed as the equivalent to tannic acid (mg TE/100g DW).

\section{Determination of Betalain Content}

The content of betaxanthins and betacyanins in the extracts was determined spectrophotometrically at $538 \mathrm{~nm}$ and $480 \mathrm{~nm}$ respectively using UV-Vis spectrometer, according to the methods of (Ravichandran et al. [25]). The betalain content (BC) was calculated from the equation

$\mathrm{BC}(\mathrm{mg} / \mathrm{L})=[(\mathrm{A} \times \mathrm{DF} \times \mathrm{MW} \times 1000) /(\mathrm{e})]$, where $\mathrm{A}$ is the absorption, DF the dilution factor and 1 the pathlength $(1 \mathrm{~cm})$ of the cuvette. For quantification of betacyanins and betaxanthins, the molecular weights (MW) and molar extinction coefficients (e) respectively are (MW=550 $\mathrm{g} / \mathrm{mol} ; \mathrm{e}=60,000 \mathrm{~L} / \mathrm{mol} \mathrm{cm}$ in $\mathrm{H} 2 \mathrm{O})$ and $(\mathrm{MW}=308 \mathrm{~g} / \mathrm{mol} ; \mathrm{e}=48,000$ $\mathrm{L} / \mathrm{mol} \mathrm{cm}$ in $\mathrm{H} 2 \mathrm{O}$ ) were applied.

\section{Yield measurement}

The extraction yield $(\%, w / w)$ was measured by the following equation.

$$
\text { Yield }(\%)=(\mathrm{W} 1 / \mathrm{W} 2 \times 100)
$$

Where W1 is the weight of the extract after solvent evaporation and W2 is the weight of the plant powder

\section{Viability of Ehrlich Ascites Carcinoma Cells (EACC)}

Cancer cells were incubated with various extracts of opuntia ficus indica peels and saline as control for $2 \mathrm{~h}$ then the viability was determined by the modified cytotoxic trypan blue-exclusion technique as described by Bennett et al. [26].

A line of Ehrlich Ascities Carcinoma was obtained from National Cancer Institute (NCI) Cairo, Egypt. The tumor cell line was maintained in female Swiss albino mice by weekly intraperitoneal (ip) transplantation of $2.5 \times 106$ cells/ mouse.

\section{Determination of antioxidant efficiency}

\section{Free radical scavenging activity}

The free radical scavenging capacity of various extracts of opuntia ficus peels was measured using $\alpha, \alpha$ - diphenyl- $\beta$-picrilhydrazyl (DPPH) assay (Juntachote and Berghofer [27]). The absorbance of the samples was measured at $517 \mathrm{~nm}$. The radical-scavenging activity was expressed as percentage of inhibition and calculated using the following formula:

$\%$ inhibition $=[($ A control - A sample $) /($ A control $)] \times 100$.

Where, $A$ is absorbance at $517 \mathrm{~nm}$.

\section{Determination of reducing power}

The ability of the tested extracts to reduce $\mathrm{Fe}^{3+}$ was assayed by the method of Chou et al. [28]. The absorbance was measured at $700 \mathrm{~nm}$. The results were expressed as $\mu \mathrm{g}$ of gallic acid equivalent per $100 \mathrm{~g}$ DW.

\section{Isolation and identification of phenolic constituents}

\section{Thin layer chromatography (TLC)}

The ethanol (80\%) extract of Prickly pear peels (Opuntia ficusindica) was fractionated using thin layer chromatography (TLC) technique. The extract was applied on silica gel 60 F254 TLC aluminum sheets (20 x20) (Merck, Darmstadt, Germany) at one of extremes to separate the different fractions. The ethanol extract was developed with combinations of petroleum ether / ethyl acetate solvents (9:1, 8.5:1.5, 8:2, 7:3, 6:4 and 5:5 v/v) as mobile phase. The separated fractions (1-9) by using mixture of petroleum ether / ethyl acetate $(5: 5 \mathrm{v} / \mathrm{v})$ which seems the best good resolution. The antioxidant and anticancer activities of these fractions were determined as mentioned while their chemical characterization was analyzed by different spectrophotometric techniques, as follows: 


\section{a) Mass spectroscopic (MS) Analysis of potent fractions}

The potent two fractions of Prickly pear peels were analyzed by Mass spectrum (MS). The mass spectrometer was scanned over the 40 to $400 \mathrm{~m} / \mathrm{z}$ range with an ionizing voltage of $70 \mathrm{eV}$. The identification was based on standard mass library of National Institute of Standards and Technology (NIST Version 2.0) to detect the possible fraction structure

\section{b) Fourier transformed infra red (FTIR) spectra}

A Perkin Elmer (Waltham, Massachusetts, USA) was used to obtain Fourier transformed infrared (FTIR) spectra (System 2000) and applied for each pure fraction analysis.

\section{c) Proton magnetic resonance Spectra (1H NMR)}

The identification of compounds was confirmed by carrying out 1H-NMR analysis using NMR Joel GIM, EX $270(400 \mathrm{~Hz})$.

\section{d) Carbon magnetic resonance Spectra (13C NMR)}

The identification of compounds was confirmed by carrying out 13C -NMR analysis using NMR Joel GIM, EX $270(400 \mathrm{~Hz})$.

\section{Statistical Analysis}

All analyses were performed in triplicate and data reported as mean. Data were subjected to analysis of variance (ANOVA) $(\mathrm{P} \leq 0.05)$.
Results were processed by Excel (Microsoft Office 2007) and SPSS Version 18.0 (SPSS Inc., Chicago, IL, USA).

\section{Results and Discussion}

Phenolic compounds are widely distributed in fruits and vegetables (Li et al. [29]), which have received considerable attention because of their potential antioxidant activities and free radical-scavenging abilities, which potentially have beneficial implications in human health (Lopez-Velez et al. [30]; Li et al. [29]; Govindarajan et al. [31]). Table 1 shows total phenolics, flavonoids, tannins, total betalains (Betacyanins \& Betaxanthins) contents and yield of different extracts of Prickly pear peels. Total phenolics of different extracts of Opuntia ficus indica peels are ranged from 221.3 to $1501.7 \mu \mathrm{g}$ gallic acid $/ 100 \mathrm{~g}$ DW. The recovery of polyphenols from plant materials is influenced by the solubility of the phenolic compounds in the solvent used for the extraction process (Nićiforović et al. [32]). Ethanol and methanolic extracts had significantly $(\mathrm{p}<0.05)$ the highest amounts of total phenolics (1501.7 and $1078 \mu \mathrm{g}$ gallic acid equivalents (GAE) / $100 \mathrm{~g}$ DW, respectively). The phenolic compounds values of water extracts was $612.10 \mu \mathrm{g}$ GAE/ $100 \mathrm{~g}$ DW. These results showed that higher amount of phenol compounds was obtained with solvent which has high polarity. These findings may be due to the fact that phenolics are often extracted in higher amounts in more polar solvents such as aqueous methanol/ethanol as compared with absolute methanol/ ethanol (Sultana et al. [33]).

\begin{tabular}{|c|c|c|c|c|c|c|}
\hline \multirow[b]{2}{*}{ Extract } & \multirow[b]{2}{*}{ Total polyphenols } & \multirow[b]{2}{*}{ Flavonoids } & \multirow[b]{2}{*}{ Tannins } & \multicolumn{2}{|l|}{ Total betalains } & \multirow{3}{*}{$\begin{array}{l}\text { Yield \% } \\
\qquad 64.74^{\mathrm{a}} \pm 0.42\end{array}$} \\
\hline & & & & Betacyanins $\mathrm{mg} / \mathrm{L}$ & Betaxanthinsb $\mathrm{mg} / \mathrm{L}$ & \\
\hline $\begin{array}{l}\text { Ethanol/water } \quad(80: 20 \\
\mathrm{v} / \mathrm{v})\end{array}$ & $1501.7^{\mathrm{a}} \pm 2.0$ & $472.33^{a} \pm 4.67$ & $72.14^{\mathrm{a}} \pm 2.52$ & $0.735^{b} \pm 0.09$ & $1.045^{b} \pm 0.02$ & \\
\hline Chloroform & $352.3^{\mathrm{e}} \pm 1.1$ & $127.43^{\mathrm{e}} \pm 2.21$ & $26.11^{d} \pm 7.61$ & $0.412^{\mathrm{c}} \pm 0.001$ & $0.431^{d} \pm 0.00$ & $4.8^{f} \pm 0.46$ \\
\hline Ethyl acetate & $221.3^{9} \pm 0.11$ & $90.56^{f} \pm 0.4$ & $13.42^{\mathrm{e}} \pm 1.24$ & $0.080^{e} \pm 0.001$ & $0.072^{e} \pm 0.004$ & $6.18^{e} \pm 0.10$ \\
\hline Acetone & $241.2^{f} \pm 0.05$ & $74.12^{9} \pm 0.12$ & $19.75^{d} \pm 1.75$ & $0.178^{d} \pm 0.001$ & $0.147^{\mathrm{e}} \pm 0.00$ & $2.5^{9} \pm 0.5$ \\
\hline Ethanol & $848.9^{c} \pm 4.44$ & $326.30^{c} \pm 5.0$ & $47.31^{b} \pm 2.91$ & $0.395^{\circ} \pm 0.001$ & $0.429^{d} \pm 0.007$ & $34.13^{\mathrm{d}} \pm 1.00$ \\
\hline Methanol & $1078^{\mathrm{b}} \pm 0.57$ & $356.90^{\mathrm{b}} \pm 3.4$ & $48.91^{b} \pm 0.29$ & $0.247^{d} \pm 0.009$ & $0.594^{c} \pm 0.001$ & $50.7^{b} \pm 0.4$ \\
\hline Distilled water & $612.1^{d} \pm 1.9$ & $194.50^{d} \pm 3.39$ & $29.90^{\mathrm{C}} \pm 0.07$ & $2.946^{a} \pm 0.12$ & $2.062^{\mathrm{a}} \pm 0.21$ & $36.12^{\mathrm{c}} \pm 0.70$ \\
\hline LSD & 3.55 & 5.84 & 6.09 & 0.09 & 0.1 & 0.99 \\
\hline
\end{tabular}

Data are expressed as mean \pm SD. Values given represent means of three determinations. Values followed by the same letter are not significantly different $(p<0.05)$. Total polyphenols are expressed as $\mathrm{mg}$ gallic acid $/ 100 \mathrm{~g}$ of dry plant material. Flavonoids are expressed as mg catechin $/ 100 \mathrm{~g}$ of dry plant material. Tannin is expressed as $\mathrm{mg}$ tannic acid $/ 100 \mathrm{~g}$ of dry plant material. Betacyanins and Betaxanthins are expressed as $\mathrm{mg} / \mathrm{L}$.

Table 1: Total phenolics, flavonoids, tannins, total betalains (Betacyanins \& Betaxanthins) contents and yield of different extracts of Prickly pear peels.

On the contrary, the lowest levels of phenolics were estimated in chloroform, ethyl acetate and acetone extracts of Opuntia ficus indica peels. Total flavonoid contents of Opuntia ficus indica peels, extractes are given in Table 1 . The flavonoids contents varied in the different extracts which ranged from 74.12 to $472.33 \mu \mathrm{g}$ catechin equivalents (CE) / 100 g. Ethanolic and methanolic extracts showed significantly $(\mathrm{p}<0.05)$ the highest amounts of total flavonoid content. This observation may be due to the fact that ethanol -water mixtures are highly polar and thus show greater efficacy in the extraction of polar phytochemicals such as phenolics and flavonoids (Shabir et al. [34]). However, the lowest amounts of flavonoids were measured in chloroform and acetone extracts of Opuntia ficus indica peels. The level of flavonoids in plant extracts depends on the polarity of solvents used in the extract preparation (Min and Chun-Zhao [35]). Non-polar solvents are unsuitable for extraction of polar phenolics and flavonoid compounds (Khoddami et al. [36]). Less polar flavonoids (e.g., isoflavones, flavanones, methylated flavones, and flavonols) are extracted with chloroform, dichloromethane, diethyl ether, or ethyl 
acetate, while flavonoid glycosides and more polar aglycones are extracted with alcohols or alcohol-water mixtures (Marston and Hostettmann [37]).

Tannins are another major group of polyphenols in our diets. Their contents in extracts obtained from opuntia ficus indica peels using various solvents are given in Table 1. Significant $(\mathrm{p} \leq 0.05)$ differences were observed between tannin contents of different solvent extracts. Indeed, ethanol/water $(80: 20 \mathrm{v} / \mathrm{v})$ had significantly the highest $(\mathrm{p} \leq$ 0.05 ) levels of tannins $72.14 \mathrm{mg}$ tannic acid /100g DW, followed by the methanolic and ethanolic extracts with a values of 48.91 and $47.31 \mathrm{mg}$ tannic acid /100g DW, respectively . On the other hand, extracts obtained with acetone and ethyl acetate had significantly the lowest tannin contents 19.75 and $13.42 \mathrm{mg}$ tannic acid /100g DW, respectively. These findings confirm with the fact that polar compounds dissolve in polar solvents and non-polar compounds in non-polar compounds. Betalains consist of two sub-classes: betacyanins (red-violet pigments) and betaxanthins (yellow-orange pigments) (Delgado-Vargas et al. [38]; Stintzing and Carle [39]). They have antimicrobial and antiviral effects (Strack et al. [10]) and also can inhibit the cell proliferation of human tumor cells (Reddy et al. [40]).

Water extracts showed significantly $(\mathrm{p}<0.05)$ the highest contents of total Betacyanins and Betaxanthins 2.94 and $2.06 \mu \mathrm{g} / \mathrm{ml}$, respectively. This finding may be due to the fact that betalains are water-soluble nitrogen-containing pigments, which are synthesised from the amino acid tyrosine and classified into two structural groups: the red-violet betacyanins and the yellow-orange betaxanthins. (Azeredo [40]; Ravichandran et al. [25]), followed by these values of ethanol extract were 0.73 and $1.04 \mu \mathrm{g} / \mathrm{ml}$, respectively. Moderate amounts of betalains were shown for chloroform, and methanol extracts. However, the lowest amounts of betalains were measured in ethyl acetate and acetone extracts of Opuntia ficus indica peels. One of the most important physicochemical properties of betalain plant pigments are their significant polarity and ionization (dissociation, zwitter-ionic behavior) in aqueous solutions. The increased polar character of betacyanins and betaxanthins results in insolubilities in any of the popular organic polar or semi-polar solvents except of water and the mixtures with low-molecular alcohols (Stintzing et al. [42]; Wybraniec et al. [43]). The yields of extracts obtained from opuntia ficus indica peels using various solvents are given in Table 1 . The yield is ranged from 2.5 to $64.74 \mu \mathrm{g} / 100 \mathrm{~g}$ of opuntia ficus indica peels. Opuntia ficus indica peels extracted with ethanol had the highest yield of extract (64.74\%) followed by methanol extracts (50.7\%). In many studies, yield of phenolics extraction showed a strong correlation with the polarity of the solvent used; high polarity solvents being the best for extraction (López et al. [44]). However, the lowest values (4.8 and $2.5 \mu \mathrm{g} / 100 \mathrm{~g}$ ) of extraction yield were recorded for chloroform and acetone extracts, respectively.

\section{Antioxidant activity}

DPPH radical scavenging activity of various solvent extracts of Prickly pear peels and synthetic antioxidant (BHT) are given in Table 2. In DPPH scavenging assay, the antioxidant activity was measured by the decrease in absorbance as the DPPH radical received an electron or hydrogen radical from an antioxidant compound to become a stable diamagnetic molecule (Juntachote and Berghofer [27]). All extracts of prickly pear peels exhibited appreciable scavenging activity ranging from $13.04 \%$ to $91.7 \%$. The free radical scavenging activities of extracts depend on the ability of antioxidant compounds to lose hydrogen and the structural conformation of these components (Aksoy et al. [45]). The DPPH radical-scavenging activity was dependent on the concentration of extracts; it increased significantly and gradually with increasing concentration of extracts (Table 2).

\begin{tabular}{|c|c|c|c|c|c|}
\hline \multirow[t]{2}{*}{ Extract } & \multicolumn{4}{|c|}{ Antioxidant activity (\%) } & \multirow{3}{*}{$\begin{array}{l}\text { Reducing power activity absorbance at } 700 \mathrm{~nm} \\
1.36^{\mathrm{a}} \pm 0.18\end{array}$} \\
\hline & $20 \mu \mathrm{g} / \mathrm{ml}$ & $40 \mu \mathrm{g} / \mathrm{ml}$ & $60 \mu \mathrm{g} / \mathrm{ml}$ & $100 \mu \mathrm{g} / \mathrm{ml}$ & \\
\hline Ethanol/water $(80: 20 \mathrm{v} / \mathrm{v})$ & $80.8 b^{c} \pm 7.50$ & $90.80^{\mathrm{a}} \pm 1.85$ & $91.7^{\mathrm{a}} \pm 1.25$ & $90.6^{\mathrm{a}} \pm 3.79$ & \\
\hline Chloroform & $19.29^{\mathrm{Im}_{ \pm}}+.09$ & $32.82^{\mathrm{j} k} \pm 2.76$ & $43.98^{n} \pm 1.93$ & $58.4^{f} \pm 2.62$ & $0.64^{b} \pm 0.08$ \\
\hline Ethyl acetate & $13.04^{\mathrm{n}} \pm 1.41$ & $18.83^{1 \mathrm{~m}} \pm 1.80$ & $17.42^{\mathrm{Imn}} \pm 2.66$ & $21.34^{\prime} \pm 2.8$ & $1.22^{\mathrm{a}} \pm 0.13$ \\
\hline Acetone & $13.60^{\mathrm{mn}} \pm 2.16$ & $23.01^{\prime} \pm 2.12$ & $30.47^{k} \pm 2.59$ & $36.53^{\mathrm{ij}} \pm 3.86$ & $1.09^{a} \pm 0.06$ \\
\hline Ethanol & $39.79^{h i} \pm 2.65$ & $61.60^{\mathrm{ef}_{ \pm}} \pm .89$ & $76.70^{\circ} \pm 1.94$ & $78.2^{c} \pm 2.72$ & $1.20^{\mathrm{a}} \pm 0.07$ \\
\hline Methanol & $62.72^{\mathrm{ef}} \pm 1.25$ & $87.04^{a} \pm 0.9$ & $90.49^{a} \pm 2.26$ & $90.4^{a} \pm 1.15$ & $1.21^{\mathrm{a}} \pm 0.12$ \\
\hline Distilled water & $68.77^{d} \pm 2.38$ & $81.08^{\mathrm{bc}} \pm 2.21$ & $86.02^{\mathrm{ab}} \pm 2.64$ & $86.48^{\mathrm{ab}} \pm 2.24$ & $1.24^{a} \pm 0.08$ \\
\hline BHT & $53.909_{ \pm 4.10}$ & $65.12^{\mathrm{de}} \pm 2.76$ & $77.10^{\circ} \pm 1.65$ & $79.06^{\circ} \pm 2.44$ & $0.78^{a} \pm 0.09$ \\
\hline LSD at 0.05 & 4.43 & & & & 0.19 \\
\hline
\end{tabular}

Table 2: DPPH radical scavenging activity and reducing power activity of various solvent extracts of Prickly pear peels and synthetic antioxidant $(\mathrm{BHT})$

Ethanol/water $(80: 20 \mathrm{v} / \mathrm{v})$, water and methanol extracts had significantly $(\mathrm{P}<0.05)$ the highest $\mathrm{DPPH}$ radical scavenging activity. As the concentration of phenolic compounds or degree of hydroxylation of the phenolic compounds increases DPPH radical scavenging activity increases, and with it antioxidant activity (Sultana et al. [46]). The antioxidant activity of phenolic compounds is mainly due to their redox properties, which can play an important role in adsorbing and neutralizing free radicals, quenching singlet and triplet 
Page 5 of 9

oxygen, or decomposing peroxides(Javanmardi et al . [47]). On the other hand, the lowest DPPH radical scavenging activity values were observed for ethyl acetate and acetone extracts. No significant differences in radical-scavenging activity were observed between BHT as synthetic antioxidant and ethanol extracts of Prickly pear peels at concentration of 60 and $100 \mu \mathrm{g} / \mathrm{ml}$. DPPH radical scavenging activity of ethanol/water $(80: 20 \mathrm{v} / \mathrm{v})$, methanol and water extracts of prickly pear peels at concentration of 40,60 and $100 \mu \mathrm{g} / \mathrm{ml}$ was also significantly higher than that of BHT (Table 2).

\section{Reducing power}

The reducing power assay is often used to evaluate the ability of an antioxidant to donate an electron (Yildirim et al. [48]). In reducing power assay, antioxidants cause the reduction of the $\mathrm{Fe}^{3+}$ into $\mathrm{Fe}^{2+}$, thereby changing the solution into various shades from green to blue, depending on the reducing power of the compounds (Ferreira et al. [49]). Results of reducing power activity of various extracts and fractions of Opuntia ficus indica peels and synthetic antioxidant (BHT) are given in Table 2. The reducing power is ranged from 0.78 to 1.364 (absorbance value). Ethanol/water $(80: 20 \mathrm{v} / \mathrm{v})$, water and methanol extracts had significantly $(\mathrm{P}<0.05)$ the highest reducing power activity. However, the lowest reducing power activity was recorded for chloroform extracts. It has been reported that the reducing power of substances is probably because of their hydrogen donating ability. Ethanol/water $(80: 20 \mathrm{v} / \mathrm{v})$, water and methanol extracts of prickly pear peels might, therefore, contain high amount of reductones than other extracts of prickly pear peels. Hence, ethanol/ water $(80: 20 \mathrm{v} / \mathrm{v})$, water and methanol extracts of prickly pear peels may act as electron donors and could react with free radicals to convert them into more stable products and then terminate the free radical chain reactions. All extracts of prickly pear peels except chloroform extracts had higher reducing power activity than that of BHT. These findings indicate that the antioxidant activity is well correlated with the amount of phenolics constituent found in the extract. Therefore, phenolic compounds of prickly pear peels are good electron donors and could terminate the radical chain reaction by converting free radical to more stable products.

Among the tested extracts, the ethanol/water $(80: 20 \mathrm{v} / \mathrm{v})$ was found to exhibit the highest phenolic, flavonoids and Tannins content, antioxidant and anticancer activities. Therefore, this extract was fractionated using TLC and the nine different fractions are separated

\begin{tabular}{|c|c|c|c|c|c|}
\hline \multirow[t]{2}{*}{ Fraction No. } & \multicolumn{4}{|c|}{ Antioxidant activity (\%) } & \multirow{2}{*}{$\begin{array}{l}\text { Reducing power activity } \\
\text { absorbance at } 700 \mathrm{~nm}\end{array}$} \\
\hline & $20 \mu \mathrm{l}$ & $40 \mu \mathrm{l}$ & $60 \mu \mathrm{l}$ & $100 \mu \mathrm{l}$ & \\
\hline 1 & $13.3^{\mathrm{ef}_{ \pm 0}} \pm .3$ & $25.3^{b} \pm 0.3$ & $26.1^{b} \pm 0.1$ & $29.4^{a} \pm 0.4$ & $1.20 \pm 0.200$ \\
\hline 2 & $10.99^{\mathrm{ij}} \pm 0.29$ & $17.5^{d} \pm 0.5$ & $18.35^{d} \pm 0.16$ & $22.6^{c} \pm 0.31$ & $1.32 \pm 0.160$ \\
\hline 3 & $8.76^{\mathrm{Im}_{ \pm}}{ }^{2} .38$ & $8.94^{1 \mathrm{Im}_{ \pm 0.5}}$ & $10.34^{\mathrm{j} \mathrm{k}} \pm 1.00$ & $10.92^{\mathrm{hi}^{\mathrm{i}}} \pm 0.96$ & $1.0 \pm 0.200$ \\
\hline 4 & $8.39^{1 \mathrm{~m}} \pm 0.22$ & $9.28^{\mathrm{k}} \pm 0.28$ & $11.09^{h i} \pm 1.00$ & $12.86^{\mathrm{efg}_{ \pm}} 1.00$ & $0.921 \pm 0.01$ \\
\hline 5 & $7.83^{\mathrm{mn}} \pm 0.45$ & $9.6 \mathrm{gjk}_{ \pm 0} .32$ & $10.9^{\mathrm{jik}} \pm 0.51$ & $13.89^{\mathrm{e}} \pm 1.00$ & $0.811 \pm 0.01$ \\
\hline 6 & $6.7^{n} \pm 0.20$ & $7.36^{m n} \pm 0.26$ & $9.50^{\mathrm{jk}} \pm 0.5$ & $11.36^{h_{i}} \pm 0.36$ & $0.311 \pm 0.05$ \\
\hline 7 & $6.43^{n} \pm 0.23$ & $6.89^{n} \pm 1.00$ & $11.8^{\mathrm{h}} \pm 0.42$ & $12.39^{\mathrm{fgh}} \pm 0.22$ & $0.32 \pm 0.01$ \\
\hline 8 & $7.45^{\mathrm{mn}} \pm 0.21$ & $9.59^{\mathrm{jk} \mathrm{l}} \pm 0.28$ & $9.72^{\mathrm{jk} \mathrm{l}} \pm 0.39$ & $12.02^{g h^{2}} \pm 0.01$ & $0.19 \pm 0.04$ \\
\hline 9 & $5.12^{\circ} \pm 1.00$ & $7.36^{\mathrm{mn}} \pm 0.36$ & $7.82^{\mathrm{mn}} \pm 0.47$ & $11.64^{\mathrm{hi}_{ \pm}} \pm 0.33$ & $0.16 \pm 0.005$ \\
\hline LSD at 0.05 & \multicolumn{4}{|l|}{0.87} & 0.62 \\
\hline
\end{tabular}

Table 3: DPPH radical scavenging activity and reducing power activity of fractions of ethanol/water (80:20 v/v) extract of Prickly pear peels

These fractions were screened for their antioxidant capacity using DPPH radical scavenging activity and reducing power assays. Fractions 1, 2, 8 and 9 constituted the major fractions of ethanol/water $(80: 20 \mathrm{v} / \mathrm{v})$ extract $18,18,14$ and $13 \%$ respectively. As shown in Table 3 , all the fractions of ethanol/water (80:20 v/v) extract showed noticeable DPPH scavenging activities and the scavenging activity increased with the concentration increasing. Among of the nine fractions, 1 and 2 fractions showed significantly $(\mathrm{P}<0.05)$ the highest $\mathrm{DPPH}$ radical scavenging activity at every concentration. These findings reveal that the fractions from ethanol/water $(80: 20 \mathrm{v} / \mathrm{v})$ extract are free radical scavengers and able to react with the DPPH radical, which might be attributed to their electron donating ability. Similarly, the highest reducing power values (1.20 and 1.32 absorbance units) were observed for fractions 1 and 2, respectively (Table 3). The trend reducing power activity of fractions 1 and 2 for did not vary markedly from their DPPH free radical scavenging activities. It may be concluded from the results of DPPH and reducing power assays that these fractions have high levels of antioxidants.

\section{Anticancer activity against Ehrlich ascities carcinoma cells}

In the present work, trypan blue assay was used for evaluation of the anticancer activity of the different extracts in addition to nine fractions derived from ethanol $80 \%$ extract of Opuntia ficus indica peel. This assay has been widely used to investigate the ability of plant extracts and fractions and or pure compounds of those, to act as anticancer. The percent anticancer activities of Opuntia ficus indica 
Citation: Abou-Elella FM, Ali RFM (2014) Antioxidant and Anticancer Activities of Different Constituents Extracted from Egyptian Prickly Pear

Page 6 of 9

extracts were summarized in Table 4. The highest percent of Anticancer activity was observed by chloroform and ethanol extracts ( $96 \%$ and $83 \%$, respectively), followed by acetone while aqueous residue showed lower anticancer activity. At all concentrations tested, all extracts exhibited dose -dependent anticancer activity. Detailed analysis for the values listed in Table 4 and the results suggested that extracts obtained by chloroform and ethanol represented good anticancer agents.

Nine fractions (E1-E9) were isolated using TLC were tested for their anticancer activity and the data are given in Table 4 . Two fractions (E8-E9) gave high anticancer activity as $51,70 \%$, respectively therefore these two fractions chemically identified using spectroscopic analysis. The other seven fractions (1-7) came in the second rank which gave low anticancer activity Table 4 . The highest anticancer activity of the extracts may be due to the presence of betanin pigments which identified in ethanolic fractions. These results are in agreement with other studies which suggested that the cactus pear fruit extract inhibits the proliferation of skin and lung cancer ( Kapadia et al. [50]). The antiproliferative effect of betanin, isolated from the fruits of Opuntia ficus indica, was evaluated on human chronic myeloid leukemia cell line (K562) and the results show dose and time dependent decrease in the proliferation of K562 cells treated with betanin. Sreekanth et al. [51] Also this study revealed the apoptotic characteristics such as chromatin condensation, cell shrinkage and membrane blebbing DNA fragmentation pattern of cells treated with betanin. Flow cytometric analysis of cells treated with $40 \mathrm{mM}$ betanin showed $28.4 \%$ of cells in sub G0/G1 phase. Betanin treatment to the cells also induced the release of cytochrome $\mathrm{c}$ into the cytosol, down regulation $\mathrm{Bcl}-2$, and reduction in the membrane potentials. These studies demonstrated that betanin induces apoptosis in K562 cells through the intrinsic pathway. (Loro et al. [52] and Sreekanth et al. [51]).

The anticancer effect of ethanolic extract may be due to presence of Betanin, which, effectively inhibited lipid peroxidation and heme decomposition, suggesting that these pigment may provide protection against certain oxidative stress-related disorders as reported by Kanner et al. [53]. Also the highest anticancer activity of ethanolic extract may be due to presence of higher percent of poly phenols that play an important role in antioxidant activity (Wu et al. [4]) and have evidently shown antiproliferative activity or cytotoxicity to human oral cancer cells (Seeram and Heber [54]), melanoma cells (Rodriguez et al. [55]), and lung metastasis induced by B16F10 melanoma cells (Menon and Kuttan [56]).

\begin{tabular}{|c|c|c|c|c|c|}
\hline Control & $\begin{array}{l}\text { Dead cells / } 20 \mu \mathrm{g} / \\
\mathrm{ml}\end{array}$ & Dead cells / $50 \mu \mathrm{g} / \mathrm{ml}$ & Dead cells / $100 \mu \mathrm{g} / \mathrm{ml}$ & Fraction & Dead cells $/ 100 \mu \mathrm{g} / \mathrm{ml}$ \\
\hline Ethanol/water $(80: 20 \mathrm{v} / \mathrm{v})$ & $0.0^{1} \pm 0.0$ & $0.0^{1} \pm 0.0$ & $0.0^{1} \pm 0.0$ & E1 & $4.0^{f} \pm 0.56$ \\
\hline Chloroform & $22^{k} \pm 0.1$ & $30^{\mathrm{d}} \pm 1.0$ & $83^{b} \pm 0.31$ & E2 & $24.5^{\mathrm{c}} \pm 0.57$ \\
\hline Ethyl acetate & $18^{h} \pm 0.2$ & $27^{\mathrm{e}} \pm 0.5$ & $97^{a} \pm 0.02$ & E3 & $9.0^{\mathrm{e}} \pm 0.2$ \\
\hline Acetone & $23^{f} \pm 1.0$ & $10^{1} \pm 0.34$ & $0.0^{1} \pm 0.0$ & E4 & $12.0^{\mathrm{d}} \pm 0.4$ \\
\hline Ethanol & $9_{ \pm 0.5}$ & $33^{c} \pm 1.0$ & $24^{f} \pm 0.31$ & E5 & $4.0^{f} \pm 0.5$ \\
\hline Methanol & $20^{9} \pm 1.0$ & $11^{i} \pm 1.0$ & $0.0^{\prime} \pm 0.0$ & E6 & $4.0^{f} \pm 0.3$ \\
\hline \multirow[t]{3}{*}{ Distilled water } & $24^{f} \pm 1.0$ & $0.0^{\prime} \pm 0.0$ & $8.0 \mathrm{j}_{ \pm 0.5}$ & E7 & $9.0^{\mathrm{e}} \pm 0.2$ \\
\hline & & & & E8 & $76.0^{\mathrm{a}} \pm 0.5$ \\
\hline & & & & E9 & $51.5^{\mathrm{b}} \pm 0.35$ \\
\hline LSD at 0.05 & \multicolumn{3}{|l|}{1.13} & & 0.74 \\
\hline
\end{tabular}

Table 4: Anticancer activity of various solvent extracts of Prickly pear peels and ethanol/water (80:20 v/v) fractions.

\section{Spectroscopic results of opuntia ficus indica}

This study deals with the isolation and identification of bioactive compounds from the ethanol (80\%) extract of opuntia ficus indica peel which have anticancer and antioxidant activities. The ethanolic extract of opuntia ficus indica was first fractionated using TLC technique and nine fractions (E1-E9) were separated. The percentage of these fractions on TLC were $18,18,5,5,8,8,11,14$ and $13 \%$, respectively which are scratched and eluted with the same mobile phase, filtered, evaporated, weighed and then used in antioxidant and anticancer bioassays.

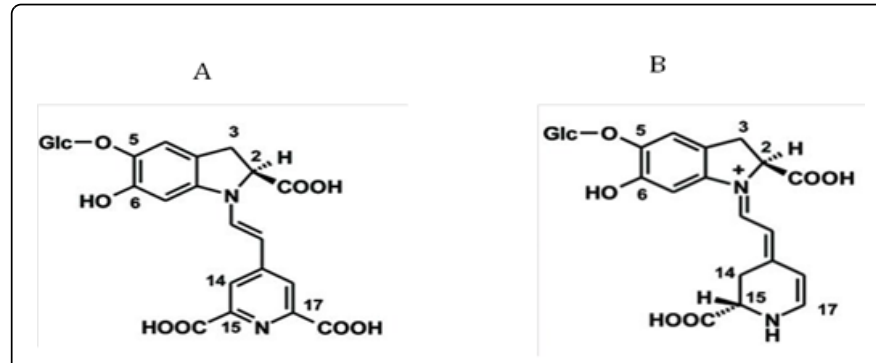

Figure 1: Chemical structure of betanin (A), chemical structure of 17-decarboxy betanin (B) 
The results revealed that fractions E8-E9 gave the highest anticancer and antioxidant activities so they were analyzed by different spectrophotometric methods. The chromatographic and spectroscopic analysis suggested two active compounds are as follows: first compound is 17-hydroxy betanin with molecular weight 507 Dalton chemical formula $\mathrm{C} 23 \mathrm{H} 26 \mathrm{~N} 2 \mathrm{O} 11$ and the second compound is betanin with molecular weight 551 Dalton and chemical formula $\mathrm{C} 24 \mathrm{H} 26 \mathrm{~N} 2 \mathrm{O} 13$ and the both are alkaloids.

The mass spectrum of compound 1 displayed a molecular ion peak $+\mathrm{M}$ at $\mathrm{m} / \mathrm{z} 506$ which suggesting the molecular formula $\mathrm{C} 24 \mathrm{H} 25 \mathrm{~N} 2 \mathrm{O} 13(+1)$ for compound 2 the presence of fragment ion peak at $\mathrm{m} / \mathrm{z}=162$ indicated the presence of hexose moiety. The presence of fragment ion peaks at $\mathrm{m} / \mathrm{z} \mathrm{73,147,191,} 204$ and 205 indicated the presence of glucose. Appearance of all these fragments confirming that the compound is betanin $(\mathrm{m} / \mathrm{z} 551)$.

The IR spectrum indicates the compounds functional groups of compound hence, compound (1) showed sharp peaks at around 1047, $3398,1274,1082,879$ and $3398 \mathrm{~cm} 1$ which indicate the presence of a carbonyl group, carboxylic acid, sugar unit in pyranose ,glycoside bond , $\beta$-glycosidic linkage and aromatic amine ,respectively.

In the IR spectrum of compound 2 the sharp peak at around 1047 , $3394,1087,1082,880,2975 \mathrm{~cm}-1$ indicate of a carbonyl group, carboxylic acid, sugar unit in pyranose, glycoside bond, $\beta$-glycosidic linkage and aromatic amine, respectively

The 1H-NMR spectrum of compound (1) indicates that the compound under study had the following type of protons; multiplex signals at $\delta$ in ppm $7.2-8.5,5,3.4-4,2-2.3$ which is characteristic for aromatic protons, anomeric proton of glucose, other sugar protons and 2- 2.3 were assigned for acid proton, respectively .

The 1H-NMR spectrum of compound (2) indicates that the compound under study had the following type of protons; multiplex signals at $\delta$ in ppm 7-8.4, 5, 3.5-4, 2-2.3 which is characteristic for aromatic protons, anomeric proton of glucose, other sugar protons and 2- 2.3 were assigned for acid proton, respectively.

13C-NMR spectrum of compound 1 confirms the presence of the most important carbon signals displayed at $\delta 174.3,167.8 \mathrm{ppm}$ which attribute to the carbonyl group $(\mathrm{C}=\mathrm{O})$ while multiplex signals at 125-132 in ppm confirm the presence of aromatic ring.

Concerning the two compounds our results are agreement with Lotfi et al. [57]) who showed that Bixa orellana L. and Opuntia tuna Mill. Are two important sources for natural colors. Bixin, betanin, isobetanin and indicaxanthin were qualitatively and quantitatively determined using TLC densitometric analysis. Also Yeddes detected three groups of compounds (flavonols, phenolic acids and betalain pigments) in methanolic extract of opuntia ficus indica. The few edible known sources of betalains are cactus fruits, such as those of Opuntia and Hylocereus genera (Stintzing et al. [58], Castellar et al. [8], Diaz et al. [4]) .The literature reports few scientific studies regarding the presence of phenols or other antioxidant compounds in cactus pear fruits. The purple cultivar has the highest concentration of total phenols, at approximately $660 \mathrm{mg} / \mathrm{l}$ juice (Butera et al. [18], Stintzing et al. [59]).

\section{Conclusion}

This study of $\mathrm{O}$. ficus indica fruit peel indicated the presence of biocompounds with possible commercial applications. These biocompounds include polyphenols, flavonoids, tannins and betalains, all of which have anticancer and antioxidant activities. These findings make Opuntia fruits peel a promising source of biologically active polyphenolic and betacyanins mixtures. The results obtained in the present study clearly demonstrate that the ethanolic and choloform extracts have fairly active compounds for in vitro anticancer and DPPH free radical scavenging activities. Also the fractions E8 -E9 showed high antioxidant and anticancer activities. In addition,our results suggest that phenolic compounds might be major contributors to the antioxidative and anticancer activities of Opuntia ficus indica peel extract. The spectroscopic analysis of promising two fractions E8E9 suggested that the first compound is 17-hydroxy betanin and the second compound is betanin. Our data may contribute to a rational basis for the use Opuntia ficus indica peel extract in possible therapy of diseases related to oxidative stress, or have potential for developing phenolic-rich extracts and fractions. Our results also indicated that inclusion of antioxidant-rich extracts (or fractions) of Opuntia ficus indica peel as a dietary supplementary has beneficial effects for human health.

\section{References}

1. Han H. and Felker P (1997) Field validation of water-use efficiency of a CAM plant Opuntia ellisiana in south Texas. J. Arid Environ 36:133-148

2. Galati EM, Tripodo MM, Trovato A, Miceli N, Monforte MT (2002) Biological effect of Opuntia ficus indica (L.) Mill. (Cactaceae) waste matter. Note I: diuretic activity. J Ethnopharmacol 79: 17-21

3. Cardador-Martinez A, Jimenez- Martinez C. and G. Sandoval (2011). Revalorization of cactus pear (Opuntia spp.) wastes as a source of antioxidants. Ciência e Tecnologia de Alimentos 31: 782-788

4. Wu X, Beecher GR, Holden JM, Haytowitz DB, Gebhardt SE et al. (2004) Lipophilic and hydrophilic antioxidant capacities of common foods in the United States. J Agric Food Chem 52: 4026-4037

5. Yeddes N, Chérif J, Guyot S Sotin H and Ayadi M (2013)Comparative Study of Antioxidant Power, Polyphenols, Flavonoids and Betacyanins of the Peel and Pulp of Three Tunisian Opuntia Forms Antioxidants. 2: 37-51

6. Castanda-Andrade I, Gonzalez -Sanchez J. and Frati- Munari A.C (1997). Hypoglycemic Effect of an Opuntia streptacanta Lemaire Dialysate. Journal of the Professional Association for Cactus Development 2: 73-75

7. Galati E.M, Mondello M.R, Guifferida D, Dugo G, Miceli N et al. (2003) Chemical characterization and biological effects of Sicilian Opuntia ficus indica (L.) Mill. Fruit Juice: Antioxidant and antiulcerogenic activity. J. Agric. Food Chem 51: 4903-4908

8. Castellar R, Obón JM, Alacid M, Fernández-López JA (2003) Color properties and stability of betacyanins from Opuntia fruits. J Agric Food Chem 51: 2772-2776

9. Díaz Medina E.M, Rodríguez Rodríguez E.M and Díaz Romero C (2007) Chemical characterization of Opuntia dillenii and Opuntia ficus indica fruits, Food Chem 103: 38-45

10. Strack D, Vogt T, Schliemann W (2003) Recent advances in betalain research. Phytochemistry 62: 247-269

11. Stintzing, F.C, Carle R (2006) Cactus fruits-More than colour. Fruit Process 16: 166-171

12. Kuti J.O (2004).Antioxidant compounds from four Opuntia cactus pear fruit varieties. Food Chem 85: 527-533

13. Zakharova NS, Petrova TA (1998) [Relationship between the structure and antioxidant activity of various betalains. Prikl Biokhim Mikrobiol 34: 199-202

14. Gentile C, Tesoriere L, Allegra M, Livrea MA, D'Alessio P (2004) Antioxidant betalains from cactus pear (Opuntia ficus-indica) inhibit endothelial ICAM-1 expression. Ann N Y Acad Sci 1028: 481-486. 
15. Andres-Lacueva C, Zamora-Ros R (2010) Wanted: specific nutritional biomarkers for food consumption for the study of its protective role in health. Br J Nutr 103: 307-308.

16. Wallace R.S. (1986). Biochemical taxonomy and the Cactaceae. Cactus Succul. J. 58, 35-38

17. Kuti, J.O. (2000). Antioxidant activity of Opuntia cactus pear. Hort Sci. $35,433$.

18. Butera D, Tesoriere L, Di Gaudio F, Bongiorno M.; Allegra M, (2002) Antioxidant activities of Sicilian prickly pear (Opuntia ficus indica) fruit extracts and reducing properties of its betalains: Betanin and indicaxanthin. J. Agric. Food Chem. 50, 6895-6901.

19. Kuti, J.O. (1992). Growth and compositional changes during the development of prickly pear fruit. J. Hortic. Sci. 67, 861-868.

20. Shahidi F, Wanasundara PK (1992) Phenolic antioxidants. Crit Rev Food Sci Nutr 32: 67-103.

21. Aires V, Adote S, Hichami A, Moutairou K, Boustani ES, et al. (2004) Modulation of intracellular calcium concentrations and $\mathrm{T}$ cell activation by prickly pear polyphenols. Mol Cell Biochem 260: 103-110.

22. AOCS. (1990). In: Official methods and recommended practices of the American Oil Chemicsts' Society (4th ed.). Champaign: American Oil Chemists' Society.

23. Meda A, Lamien C.E, Romito M, Millogo J \& Nacoulma O. G (2005) Determination of the total phenolic, flavonoid and proline contents in burkina fasan honey, as well as their radical scavenging activity. Food Chemistry 91: 571-577.

24. Polshettiwar S. A, Ganjiwale R.O., Wadher S. J \& Yeole P. G (2007).Spectrophotometric estimation of total tannis in some Ayurvedic Eye Drops. Indian J. Pharmaceutical Sciences 69: 574-576.

25. Ravichandran K, N.M.M.T, Saw A.A.A, Mohdaly, A.M.M Gabr and A. Kastell et al., (2013). Impact of processing of red beet on betalain content and antioxidant activity. Food Res. Int. 50: 670-675.

26. Bennett JM, Catovsky D, Daniel MT, Flandrin G, Galton DA, et al. (1976) Proposals for the classification of the acute leukaemias. FrenchAmerican-British (FAB) co-operative group. Br J Haematol 33: 451-458.

27. Juntachote T, Berghofer E (2005) Antioxidative properties and stability of ethanolic extracts of Holy basil and Galangal. Food Chem. 92:193-202

28. Chou HJ, Kuo JT, Lin ES (2009). Comparative antioxidant properties of water extracts from different parts of beefsteak plant (Perilla frutescens) J. Food Drug Anal. 17:489-496.

29. Li B.B Smith B. and Hossain Md. M (2006) Extraction of phenolics from citrus peels: I. Solvent extraction method. Separation and Purification Technology 48: 182-1883

30. López-Vélez M, Martínez-Martínez F, Del Valle-Ribes C (2003) The study of phenolic compounds as natural antioxidants in wine. Crit Rev Food Sci Nutr 43: 233-244.

31. Govindarajan R, Singh DP, Rawat AK (2007) High-performance liquid chromatographic method for the quantification of phenolics in 'Chyavanprash' a potent Ayurvedic drug. J Pharm Biomed Anal 43: 527-532.

32. Nï̈, iforovï̈. N, Mihailovi Ä V, Maskovi et al. (2010) Antioxidant activity of selected plant species; potential new sources of natural antioxidants. Food Chem Toxicol 48: 3125-3130.

33. Sultana B, Anwar F, Ashraf M (2009) Effect of extraction solvent/ technique on the antioxidant activity of selected medicinal plant extracts. Molecules 14: 2167-2180.

34. Shabir G, Anwar F, Sultana B, Khalid Z M, Afzal M et al. (2011) Antioxidant and Antimicrobial Attributes and Phenolics of different Solvent Extracts from Leaves, Flowers and Bark of Gold Mohar [Delonix regia (Bojer ex Hook.) Raf. Molecules 16: 7302-7319

35. Min G and Chun-Zhao L (2005) World Microbiol. Biotechnol 21: 1461-1463.

36. Khoddami A, Wilkes MA, Roberts TH (2013) Techniques for analysis of plant phenolic compounds. Molecules 18: 2328-2375.
37. Marston A and Hostettmann K (2006) In: Flavonoids- Chemistry, Biochemistry and Applications (M. Andersen, K.R. Markham, Eds.) Taylor \& Francis Group, London 2-3.

38. Delgado-Vargas F, Jiménez A. R, \& Paredes-López O (2000) Natural pigments: Carotenoids, anthocyanins, and betalains- characteristics, biosynthesis, processing, and stability. Critical Reviews in Food Science and Nutrition 40: 173-289.

39. Stintzing F. C \& Carle R (2004) Functional properties of anthocyanins and betalains in plants, food and in human nutrition. Trends in Food Science and Technolgy 15: 19-38

40. Reddy K M, Ruby L, Lindo A \& Nair G. M (2005) Relative inhibition of lipid peroxidation, cyclooxygenase enzymes and human tumor cells prolifieration by natural food color. Journal of Agricultural and Food Chemistry 53: 9268-9273.

41. Azeredo, H. M. C. (2009) Betalains: properties, sources, applications, and stability: A review. International Journal of Food Science \& Technology, 44: 2365-2376.

42. Stintzing FC, Conrad J, Klaiber I, Beifuss U, Carle R (2004) Structural investigations on betacyanin pigments by LC NMR and 2D NMR spectroscopy. Phytochemistry 65: 415-422.

43. Wybraniec S, Nowak-Wydra B, Mitka K, Kowalski P, Mizrahi Y (2007) Minor betalains in fruits of Hylocereus species. Phytochemistry 68 251-259.

44. López A, Rico M, Rivero A and deTangil M.S (2011) The effects of solvents on the phenolic contents and antioxidant activity of Stypocaulon scoparium algae extracts. Food Chem 125:1104-1109.

45. Aksoy L, Kolay E, Agilonu Y, Aslan Z and Kargioglu M (2013) Free radical scavenging activity, total phenolic content, total antioxidant status, and total oxidant status of endemic Thermopsis turcica. Saudi Journal of Biological Sciences 20: 235-239.

46. Sultana B, Anwar F, Przybylski R. (2007) Antioxidant activity of phenolic components present in barks of Azadirachta indica,Terminalia arjuna, Acacia nilotica, and Eugenia jambolana Lam. trees. Food Chem 104: 1106-1114.

47. Javanmardi J, Stushnoff C, Locke E and Vivanco J.M (2003). Antioxidant activity and total phenolic content of Iranian Ocimum accessions. Food Chemistry 83: 547-550.

48. Yildirim A, Mavi A, Oktay M, Kara AA, Algur OF et al. (2000) Comparison of antioxidant and antimicrobial activities of tilia (Tilia argentea Desf ex DC), sage (Salvia triloba 1.), and black tea (Camellia sinensis) extracts. J Agric Food Chem 48: 5030-5034.

49. Ferreira I.C.F.R, Baptista P, Vilas-Boas M and Barros L (2007) Freeradical scavenging capacity and reducing power of wild edible mushrooms from northeast Portugal: individual cap and stipe activity. Food Chemistry 100 4: 1511-1516.

50. Kapadia GJ, Tokuda H, Konoshima T, Nishino H (1996) Chemoprevention of lung and skin cancer by Beta vulgaris (beet) root extract. Cancer Lett 100: 211-214.

51. Sreekanth D, Arunasree MK, Roy KR, Chandramohan Reddy T, Reddy $\mathrm{GV}$, et al. (2007) Betanin a betacyanin pigment purified from fruits of Opuntia ficus-indica induces apoptosis in human chronic myeloid leukemia Cell line-K562. Phytomedicine 14: 739-746.

52. Loro JF, del Rio I, Pérez-Santana L (1999) Preliminary studies of analgesic and anti-inflammatory properties of Opuntia dillenii aqueous extract. J Ethnopharmacol 67: 213-218.

53. Kanner J, Harel S, Granit R (2001) Betalains-a new class of dietary cationized antioxidants. J Agric Food Chem 49: 5178-5185.

54. Seeram N.P, Adams L.S, Hardy M.L and Heber D (2004) Total cranberry extract versus its phytochemical constituents: antiproliferative and synergistic effects against human tumor cell lines. J Agric Food Chem 52:2512-7.

55. Rodriguez J, Yáñez J, Vicente V, Alcaraz M, Benavente-García O et al (2002) Effects of several flavonoids on the growth of B16F10 and SKMEL-1 melanoma cell lines: relationship between structure and activity. Melanoma Res 12: 99-107. 
Citation: Abou-Elella FM, Ali RFM (2014) Antioxidant and Anticancer Activities of Different Constituents Extracted from Egyptian Prickly Pear Cactus (Opuntia Ficus-Indica) Peel . Biochem Anal Biochem 3: 158. doi:10.4172/2161-1009.1000158

Page 9 of 9

56. Menon LG, Kuttan R, Kuttan G (1995) Inhibition of lung metastasis in mice induced by B16F10 melanoma cells by polyphenolic compounds. Cancer Lett 95: 221-225.

57. Lotfi M, Hassan R, Tawfik W and Habib A (2008) Determination of Natural Colors by Thin Layer Chromatography. Journal of Applied Sciences Research 4: 2013-2017.

58. Stintzing, F.C, Schieber A \& Carle R (2002) Identification of betalains from yellow beet (Beta vulgaris L.) and cactus pear Opuntia ficus-indica
(L.) Mill.] by high-performance liquid chromatography-electrospray ionization mass spectroscopy. Journal of Agricultural and Food Chemistry 50: 2302-2307.

59. Stintzing F.C, Herbach KM, Mosshammer MR, Carle R, Yi W et al. (2005) Color, betalain pattern, and antioxidant properties of cactus pear (Opuntia spp.) clones. J Agric Food Chem 53: 442-451. 